ARENALES, A., BASSO, K.M. e CALDERÓN, C. Tumor de mama em cães: marcadores prognósticos e imunohistoquímica (COX-2, E-caderina, Receptores hormonais e Ki-67) revisão de literatura. PUBVET, Londrina, V. 8, N. 22, Ed. 271, Art. 1806, Novembro, 2014.

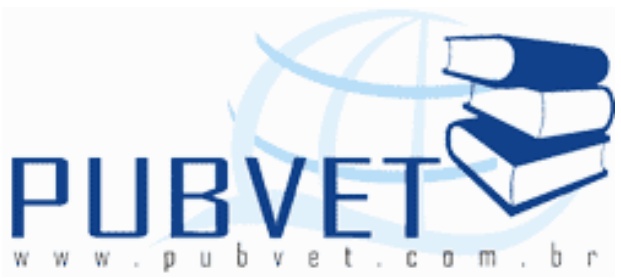

PUBVET, Publicações em Medicina Veterinária e Zootecnia.

\title{
Tumor de mama em cães: marcadores prognósticos e imunohistoquímica (COX-2, E-caderina, Receptores hormonais e Ki-67) - revisão de literatura
}

Alexandre Arenales ${ }^{1}$, Karina Maria Basso ${ }^{2}$, Celmira Calderón ${ }^{3}$

1 Residente em Anatomia Patológica Veterinária; Faculdade de Medicina Veterinária de Araçatuba; Universidade Estadual Paulista "Júlio de Mesquita Filho" - Campus de Araçatuba

${ }^{2}$ Pós Graduanda em Ciência Animal, Universidade Estadual de Londrina

3 Professora Doutora em Anatomia Patológica Veterinária; Departamento de Patologia Geral; Universidade Estadual do Norte do Paraná - Campus de Bandeirantes

\section{Resumo}

As neoplasias mamárias são um grande desafio na oncologia veterinária, e devido ao seu comportamento variável e desfecho frustrante, os parâmetros clássicos podem ser complementados por exames moleculares, principalmente pela imunohistoqúimica, o que resulta em uma maior elucidação do quadro, em especial ao prognóstico. Este trabalho tem o objetivo de revisar fatores prognósticos equatro imunomarcadoresde importância para as neoplasias mamárias de cadelas, sendo estes: COX-2, E-caderina, Receptores hormonais e Ki-67.

Palavras-chave: Neoplasia mamáriacanina;Receptor de estrógeno alfa. 
ARENALES, A., BASSO, K.M. e CALDERÓN, C. Tumor de mama em cães: marcadores prognósticos e imunohistoquímica (COX-2, E-caderina, Receptores hormonais e Ki-67) revisão de literatura. PUBVET, Londrina, V. 8, N. 22, Ed. 271, Art. 1806, Novembro, 2014.

\title{
Canine mammary tumors: prognostic markersand immunohistochemistry (COX-2, E-Cadherin, hormonal receptors and Ki-67) - Review
}

\begin{abstract}
Canine mammary tumors are a big challenge in veterinary oncology, and due its variable behavior and frustrating outcome, classics parameters can be complemented by molecular tests, mainly by immunohistochemistry, which results in a greater elucidation of the clinical framework, especially to prognosis. This paper has the aimto review prognosis factors and four immunomarkersof importance for canine mammary tumors, being these: COX2, E-cadherin, Receivers hormonal and Ki-67.
\end{abstract}

Keywords: Canine mammary tumors; Estrogen Receptor Alpha.

\section{Introdução}

Nos últimos anos houve um aumento da prevalência de animais de companhia diagnosticados com neoplasias, justificada pela maior expectativa de vida dos animais, resultado de melhor nutrição, imunização e avanços na prevenção e tratamento de várias doenças ${ }^{45}$. Assim como nos seres humanos, as neoplasias em animais de estimação têm ocorrência espontânea, o que torna os cães excelentes modelos para o estudo da oncologia comparada, biologia do câncer, investigações clínicopatológicas e avaliação de novas drogas terapêuticas, e dentre as neoplasias dos cães, se destaca o tumor de mama, que compartilha com as mulheres importantes fatores clínico patológicos, histopatológicos e bioquímicos ${ }^{45,50,47}$.

As neoplasias mamárias representam o desafio mais comum na prática veterinária, com dificuldadese frustrações compartilhadas por clínicos durante o tratamento e anatomopatologistascom relação ao diagnóstico e fatores prognósticos $29,20,50,47$. Os tumores mamários representam a maior porcentagemdas neoplasias quando consideradas apenas as cadelas, sua 
ARENALES, A., BASSO, K.M. e CALDERÓN, C. Tumor de mama em cães: marcadores prognósticos e imunohistoquímica (COX-2, E-caderina, Receptores hormonais e Ki-67) revisão de literatura. PUBVET, Londrina, V. 8, N. 22, Ed. 271, Art. 1806, Novembro, 2014.

incidência é homogênea por todo o mundo, onde $50 \%$ apresentam comportamentomaligno e com altas chances de metástases. Clinicamente a maioria das cadelas são saudáveis e os tumores podem ser identificados pelo proprietário ou clínico no momento do exame físico ${ }^{4,33,42,43,20}$.

A patogenia é hormonal, sendo o ponto crítico a exposição de hormônios endógenos ovarianos durante a fase pré púbere, fato este extensamente comprovado com acompanhamento de animais castrados, nos quais os resultados demonstram que o risco de desenvolvimento da neoplasia aumenta em $0,05 \%, 8 \%$ e $26 \%$ em cadelas submetidas à ováriosalpingo histerectomia (OSH) antes do primeiro ciclo estral, antes do segundo ciclo estral e depois do segundo ou mais ciclos respectivamente ${ }^{11,27,42}$.

A literatura relata como principais dados epidemiológicos a idade, com faixa etária média de oito anos; maior incidência em animais não ováriosalpingo histerectomizados; ocorrência de múltiplos tumores em $70 \%$ dos casos; maior ocorrência com histórico do uso de progestágenos exógenos, e maior incidência nos pares de mama inguinais $5,4,20,29,42,47$.

O diagnóstico incial pode ser feito por meio de análise citopatológica do tumor, com finalidade de excluir outras neoplasias de pele e lesões não-neoplásicas, sendo essa uma técnica suficientemente sensível e específica, com altas taxas de concordância quando comparada aos resultados histopatológicos. A citopatologia também é utilizada para avaliação de metástases regionais nos linfonodos, direcionando a abordagem terapêutica e o prognóstico do paciente ${ }^{4,20,50}$.

Exceto para casos de casos de carcinoma inflamatório ou em quadros de metástase à distância,a excisão cirúrgica é a terapêutica de escolha em todos os casos de tumores de mama pois resulta em uma maior chance de cura, aumenta o tempo e a qualidade de vida do animal, além de proporcionar material para análise histopatológica 5,4,12,26,20. 
ARENALES, A., BASSO, K.M. e CALDERÓN, C. Tumor de mama em cães: marcadores prognósticos e imunohistoquímica (COX-2, E-caderina, Receptores hormonais e Ki-67) revisão de literatura. PUBVET, Londrina, V. 8, N. 22, Ed. 271, Art. 1806, Novembro, 2014.

Devido ao comportamento biológico variável das neoplasias mamárias da cadelasão necessáriosfatores que auxiliem na avaliação do prognóstico e consequentemente um tratamento adequado ${ }^{5,4,33,31,45}$, exemplificado por a classificação e graduação histopatológica, o sistema de estadiamento clínico, e marcadores moleculares acessíveis através da técnica de imunohistoquímica $5,4,31,42$.

A histopatologia é o método de diagnóstico definitivo para neoplasias mamárias, pois promove mais critérios a respeito do comportamento tumoral, graduação tumoral, presença de necrose, invasão de vasos e tecidos adjacentes, margens cirúrgica, classificação histológica e possibilidade de análise imunohistoquímica ${ }^{4,26,42}$.

A classificação morfológica das neoplasias mamáriasem cadelas um tema com contradições e divergências, principalmente pela variabilidade morfológica dos tumores no mesmo animal e no mesmo tumor ${ }^{29}$. Entretantorecentemente foram publicadoras novas propostas por Goldschmidt et al. ${ }^{15}$ e Casalli et al. ${ }^{4}$ nas quais os autores dividem os aspectos morfológicos em grupos, apresentando maiores relações ao prognóstico, e atribuição de valores preditivos para determinadas classificações, principalmente quanto à recomendação para quimioterapia.

A graduação histopatológica é um critério de avaliação da neoplasia que estima a agressividade e diferenciação do tumor. O sistema de graduação mais utilizado em pesquisas é o método de Nottingham modificado por Elston \& Ellis, e possuiboas correlações com outros fatores prognósticos ${ }^{4,5}$. A graduação divide-se em três (I, II e III) com um sistema de escore (Figura 1) onde se soma a pontuação a partir da quantidade de túbulos, pleomorfismo nuclear e índice mitótico ${ }^{4}$. 
ARENALES, A., BASSO, K.M. e CALDERÓN, C. Tumor de mama em cães: marcadores prognósticos e imunohistoquímica (COX-2, E-caderina, Receptores hormonais e $\mathrm{Ki}-67$ ) revisão de literatura. PUBVET, Londrina, V. 8, N. 22, Ed. 271, Art. 1806, Novembro, 2014.

\begin{tabular}{lc}
\hline \multicolumn{1}{c}{ Características } & Pontuação \\
\hline 1. Formaçăo de túbulos & 1 \\
Mais de $75 \%$ do tumor & 2 \\
10 a $75 \%$ do tumor & 3 \\
Menos de $10 \%$ do tumor & \\
2. Pleomorfismo nuclear & 1 \\
Núcleos de tamanho normal & 2 \\
Aumento e variaçăo no tamanho & 3 \\
Variaçăo evidente & \\
3. Contagem mitótica & \\
0 a 8 por CGA & 1 \\
9 a 16 por CGA & 2 \\
17 ou mais por CGA & 3 \\
Total da pontuaçăo & I \\
3-5 & II \\
8-9 & Grau de malignidade \\
\hline
\end{tabular}

Figura 1. Sistema de escore usado para graduação de neoplasias mamárias. Método de Nottingham modificado por Elston \& Ellis. CGA = Campo deGrande Grande Aumento, 40X (Fonte: Cassali et al, 2011 ${ }^{4}$ ).

O métodode estadiamento clínico TNM (Tumor, Nodes, Metastasis) (Figura 2), analisa a extensão da neoplasiae serve de registro eauxílio na comunicação entre clínicos ${ }^{4,26,20,31,43}$. Yamagami et $\mathrm{al}^{46}$ mostram que o estadiamento tumoral é um excelente método para definição do prognóstico, onde é claramente perceptível a queda no tempo de sobrevida conforme o aumento do grau no estadiamento (FIGURA 3). 
ARENALES, A., BASSO, K.M. e CALDERÓN, C. Tumor de mama em cães: marcadores prognósticos e imunohistoquímica (COX-2, E-caderina, Receptores hormonais e $\mathrm{Ki}-67$ ) revisão de literatura. PUBVET, Londrina, V. 8, N. 22, Ed. 271, Art. 1806, Novembro, 2014.

\begin{tabular}{|c|c|c|c|}
\hline \multicolumn{4}{|c|}{ T - Tumor primário } \\
\hline T1 & \multicolumn{3}{|c|}{$<3$ centímetros de diâmetro no máximo } \\
\hline $\mathrm{T} 2$ & \multicolumn{3}{|c|}{ 3-5 centímetros de diâmetro no máximo } \\
\hline T3 & \multicolumn{3}{|c|}{$>5$ centímetros de diâmetro no máximo } \\
\hline \multicolumn{4}{|c|}{$\mathrm{N}$ - Linfonodo regional } \\
\hline NO & \multicolumn{3}{|l|}{ Sem metástase } \\
\hline N1 & \multicolumn{3}{|c|}{ Presença de metástase } \\
\hline \multicolumn{4}{|c|}{ M - Metástase distantes } \\
\hline MO & \multicolumn{3}{|c|}{ Sem metástase detectada } \\
\hline M1 & \multicolumn{3}{|c|}{ Metástase detectada } \\
\hline \multicolumn{4}{|c|}{ Estágios } \\
\hline I: & T1 & No & M0 \\
\hline II: & $\mathrm{T} 2$ & No & MO \\
\hline III: & T3 & No & MO \\
\hline IV: & qualquer $\mathrm{T}$ & N1 & M1 \\
\hline v: & qualquer $\mathrm{T}$ & qualquer $\mathrm{N}$ & M1 \\
\hline
\end{tabular}

Figura 2. Sistema de estadiamento clínico TNM (Adaptado de LANA et al. $\left.2007^{20}\right)$.

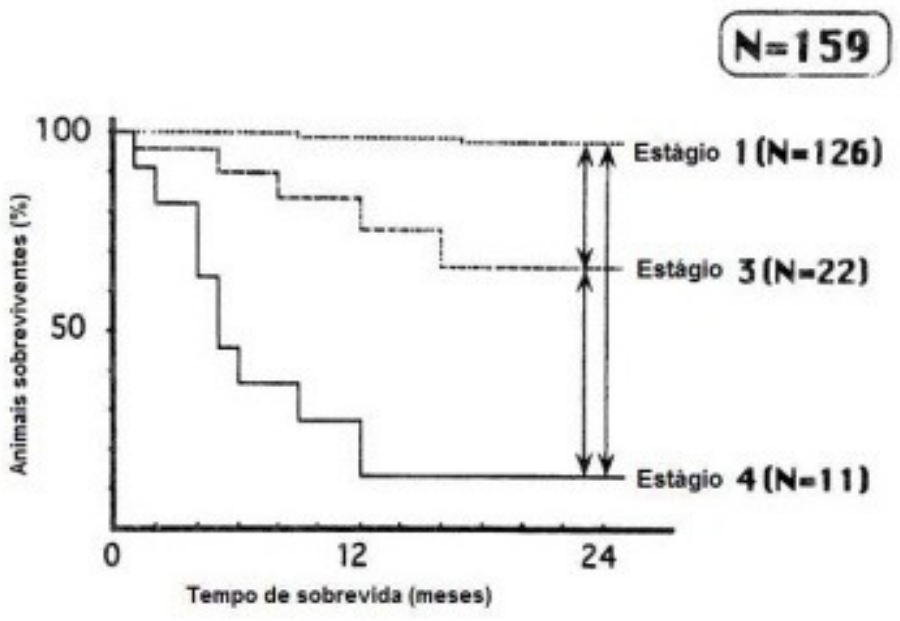

Figura 3. Relação entre a sobrevida e o estágio TNM (Adaptadode: YAMAGAMI et al, $1996^{46}$ ) 
ARENALES, A., BASSO, K.M. e CALDERÓN, C. Tumor de mama em cães: marcadores prognósticos e imunohistoquímica (COX-2, E-caderina, Receptores hormonais e Ki-67) revisão de literatura. PUBVET, Londrina, V. 8, N. 22, Ed. 271, Art. 1806, Novembro, 2014.

A oncologia veterinária tem utilizado a imunohistoquímica (IHC) para a identificação de vários marcadores relacionados ao comportamento biológico das neoplasias e avaliação de fatores prognósticos e preditivos, os quais avaliam o tumor mais criteriosamentese comparada apenas ahistopatologia ${ }^{4,48}$. Portanto devido à grande complexidade e variabilidade do desfecho das neoplasias mamárias, existe um grande interessena procura e padronização de marcadores moleculares específicos, para elucidar fatores independentes relacionados ao prognóstico ${ }^{4,48}$. A IHC tem boa aplicabilidade para diagnósticos específicos de doenças neoplásicas, poisé uma técnica com base simples e finalidade de demonstrar antígenos em uma secção histológica, devido à ligação do anticorpo específico com o antígeno específico ${ }^{37}$.

Considerando-se os métodos de classificação, graduação histológica e estadiamento clínico, ferramentas jádifundidas na medicina veterinária, hoje é importante para o médico veterinário o conhecer a utilização de imunomarcadores e sua capacidade de correlação com o comportamento tumoral e consequente prognóstico do paciente oncológico.

Essa revisão tem o objetivo de descrever os principais fatores prognosticos clássicos e imunomarcadores encontrados na literatura que estão relacionados a sobrevida em cadelas, sendo esses Ciclooxigenase-2, E-caderina, Ki-67 e receptores hormonais (Era/PR), além de uma revisão elucidação de oncologia comparada.

\section{Ciclooxigenase-2}

COX-2 é uma enzima induzida a partir de estímulos específicos como mediadores inflamatórios, hipóxia, fatores de crescimento e vários oncogenes. A COX-2é um catalisador na reação do ácido araquidônico em tromboxanos e prostaglandinas ${ }^{10,9,16,21,36}$. A atuação da COX-2 na progressão de neoplasias está relacionadacom a síntese de prostaglandina E2(PGE2), a qual contribuí 
ARENALES, A., BASSO, K.M. e CALDERÓN, C. Tumor de mama em cães: marcadores prognósticos e imunohistoquímica (COX-2, E-caderina, Receptores hormonais e $\mathrm{Ki}-67$ ) revisão de literatura. PUBVET, Londrina, V. 8, N. 22, Ed. 271, Art. 1806, Novembro, 2014.

para a proliferação tumoral (Figura 4) e atua no aumento da divisão celular, angiogênese,invasão e metástase e supressão da resposta imunológica9,16.

\section{Ácido araquidônico}

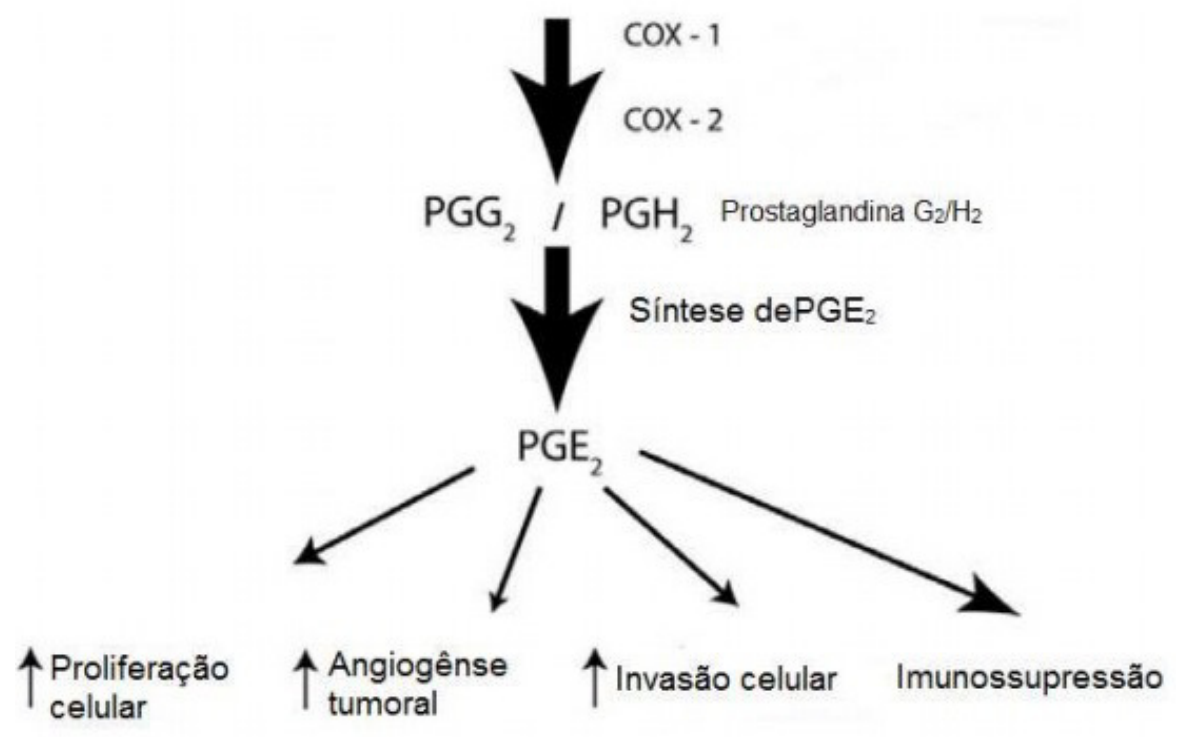

Figura 4: síntese de PGE2 a partir da COX-2, e a sua influência no desenvolvimento tumoral

A relação da COX-2 com processos neoplásicos foi descoberta com estudos epidemiológicos onde pacientes humanosque recebiam baixas e constantesdoses deanti-inflamatórios não esteriodais(AINES) apresentavam diminuição significativa no desenvolvimento de carcinoma colorretal, ehoje a expressão de COX-2 é bem relatada em vários tipos de neoplasias em humanoseanimais ${ }^{10,16}$.

Segundo Dias Pereira et $\mathrm{al}^{8} \mathrm{e}$ Lavalle et $\mathrm{al}^{21}$, provavelmente a COX-2 na glândula mamária normal de cadelasestá relacionada a processos fisiológicos de proliferação tecidual, como a inibição de apoptose, aumento da angiogênese, ativação de metalanoproteinases e a divisão celular. 
ARENALES, A., BASSO, K.M. e CALDERÓN, C. Tumor de mama em cães: marcadores prognósticos e imunohistoquímica (COX-2, E-caderina, Receptores hormonais e Ki-67) revisão de literatura. PUBVET, Londrina, V. 8, N. 22, Ed. 271, Art. 1806, Novembro, 2014.

De acordo com Dias Pereira et al. ${ }^{8}$ a intensidade e o local de expressão de COX2 variam com o grau de diferenciação celular, ou seja, quanto mais diferente do normal a célula neoplásica for, maior será sua expressão de COX-2.Desse modo a glândula mamária normal, avaliada por imunohistoquímica, expressa a COX-2em quantidade moderada aacentuada no ápice da membrana (Figura 5); as células de neoplasias benignas expressam COX-2 em quantidade moderada aacentuada na membrana e fraca no citoplasma (Figura 6); já as células malignas expressam grande quantidade de COX-2 no citoplasma (Figura 7), enquanto metástases possuem expressãoem grande quantiadena membrana e no citoplasma com intensidade igual ou maior que o tumor de origem (Figura $8)$.

Em humanos a correlação entre COX-2 e o prognóstico já foi demonstrada em vários tipos de neoplasias, incluindo o período livre da doença e o tempo de sobrevida, os quais são definidos respectivamente por:tempo entre a cirurgia e o reaparecimento do tumor eo tempo entre a cirurgia até a morte causada pela neoplasia ${ }^{16,34}$.

Nos cães, a evidência da relação entre o prognóstico e a expresão COX-2 foi demonstrada pela correlação dos níveis de expressão de COX-2 e o comportamento benigno e maligno das neoplasias mamárias, o que sabidamente está relacionada com um pior prognóstico. Do mesmo modo, altos níveis de COX-2 também são observados em casos de carcinoma inflamatório e metástases ${ }^{25,34,36}$.Além da indiferenciação celular, outros autores demonstram vários fatores clínicopatológicos correlacionados com altas expressões de COX-2, os quais estão relacionados a piores prognósticos: Millanta et al. ${ }^{25}$ demonstraram existir uma ligação significativa entre a COX-2 e a graduação histopatológica, Queiroga et al. ${ }^{34}$ que descrevem maior expressão de COX-2 está diretamente relacionado ao maior tamanho e maior ulceração tumoral, crescimento rápido e aderência a tecidos adjacentes, eQueiroga et al. ${ }^{36}$ os quais relatam que metástases regionais ou distantes e infiltração tumoral também estão relacionadas a altos níveis de expressão de COX-2. 
ARENALES, A., BASSO, K.M. e CALDERÓN, C. Tumor de mama em cães: marcadores prognósticos e imunohistoquímica (COX-2, E-caderina, Receptores hormonais e Ki-67) revisão de literatura. PUBVET, Londrina, V. 8, N. 22, Ed. 271, Art. 1806, Novembro, 2014.
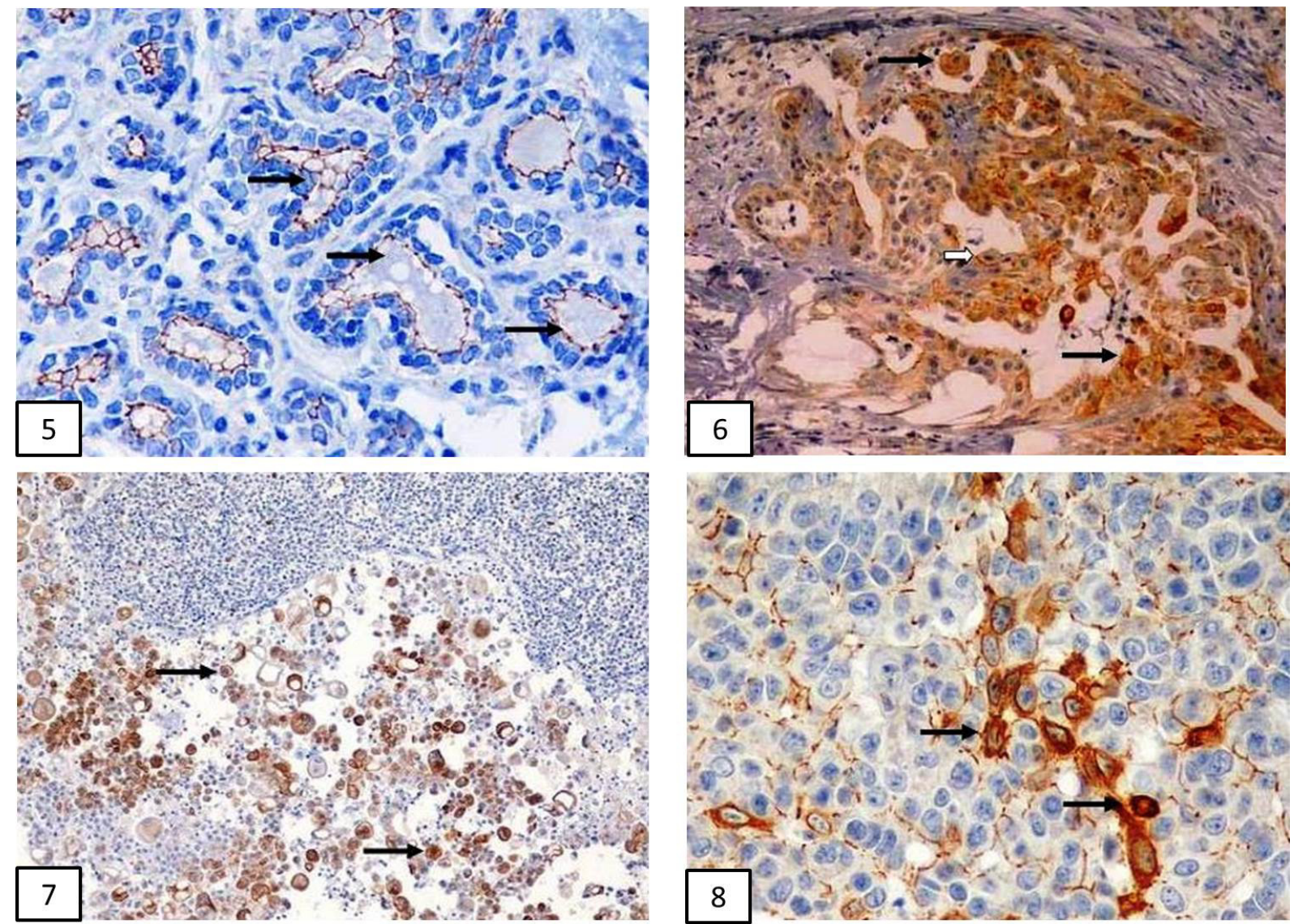

Figura 5. Glândula mamária normal. Expressão de COX-2 nas células epiteliais (região apical da membrana, setas). Cão. Imunohistoquímica. 400x.Figura 6. (Adenoma simples) Neoplasias benignas expressam COX-2 no padrão citoplasmático (seta preta) em quantidade moderada, e membranoso de maneira fraca (seta branca). Cão. Imunohistoquímica. 200x.Figura 7. (Carcinoma sólido) Neoplasias de comportamento maligno expressam COX-2 em padrão citoplasmático em grande quantidade (setas). Cão. Imunohistoquímica. 400x.Figura 8. Metástase em linfonodo. Células neoplásicas exibem marcação intensa para COX-2 em ambos os padrões (setas). Cão. Imunohistoquímica. 100x (Fonte: DIAS PEREIRA et al, 2009²)

Para uma análise mais rigorosa e precisa da validade da COX-2 como fator prognóstico, Lavalle et al. ${ }^{21}$, Millanta et al. ${ }^{25}$, Queiroga et al. ${ }^{34}$, Queiroga et al. $^{36}$ dividiram os tumores em alto e baixo grau de expressão para COX-2 para corelacionar com o tempo de sobrevida total e concluiram, de forma consensual, significativa queda no tempo de sobrevida total (OS) em animais pertencentes ao grupo de alta expressão de COX2 (Figura 9). 
ARENALES, A., BASSO, K.M. e CALDERÓN, C. Tumor de mama em cães: marcadores prognósticos e imunohistoquímica (COX-2, E-caderina, Receptores hormonais e Ki-67) revisão de literatura. PUBVET, Londrina, V. 8, N. 22, Ed. 271, Art. 1806, Novembro, 2014.

Queiroga et al. ${ }^{36}$ elucidaram o tempo livre da doença (DFS), e evidenciaram relação significativa entre altas expressões de COX-2 e menor tempo na recidiva da neoplasia após a retirada cirúrgica (Figura 10).
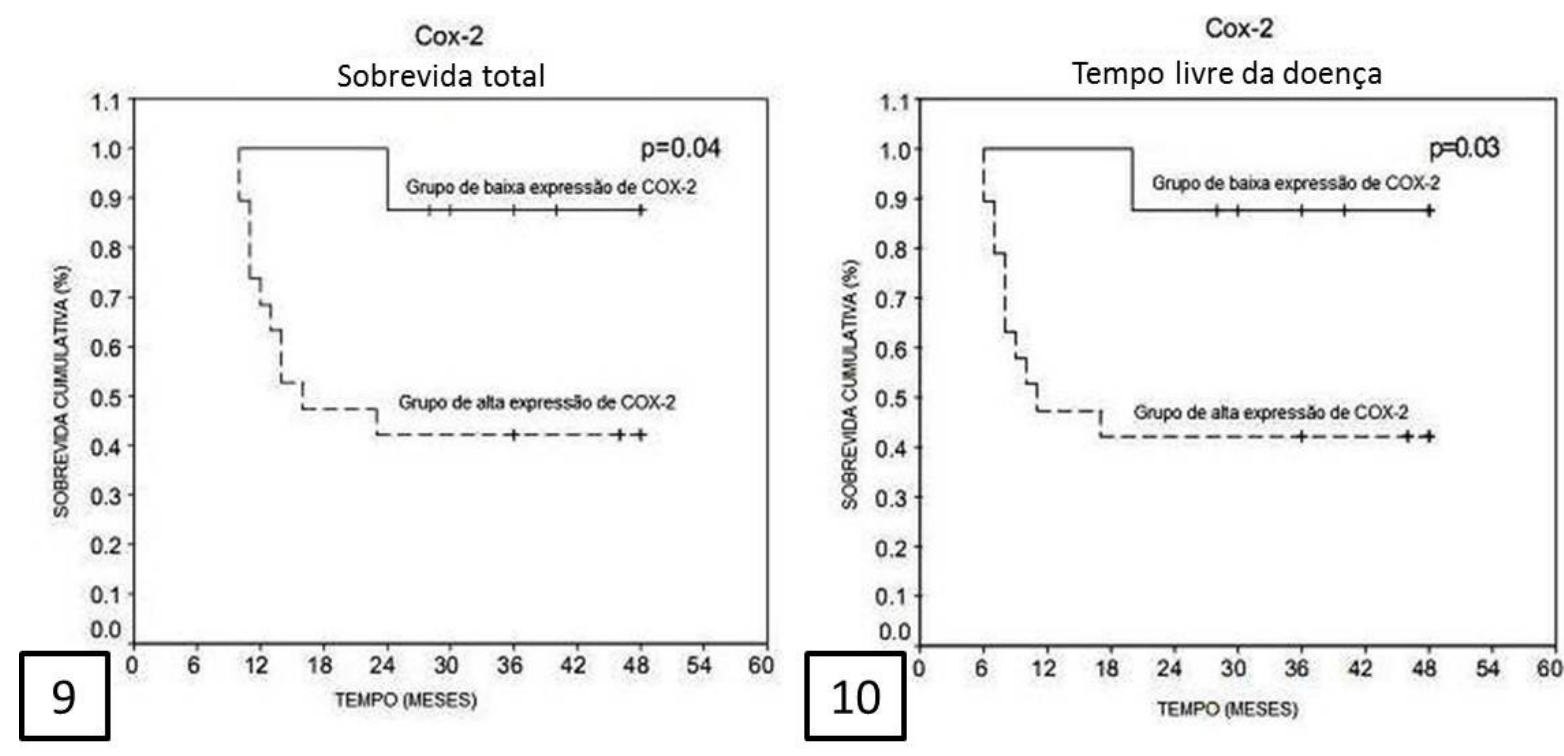

Figura 9. Correlação da alta expresão de COX-2 com menor tempo de sobrevida. Figura 10. Correlação da alta expresão de COX-2 com menor tempo de recidivas. (Adaptado de Queiroga et al, 2010 ${ }^{36}$ ).

Apesar do significativo número de estudos sobre a COX-2 e sua correlação com o tempo de sobrevida, os autores concluem que a expressão de COX-2, mesmo estatisticamente relacionada com a sobrevida, não pode ser até o presente momento considerada como um fator prognóstico independente, isto é, altas expressões tendem a resultar em um pior prognóstico, e desta forma esse dado isolado não é capaz de determinar o desfecho clínico, pois não elucida de maneira segura o comportamento biológico da neoplasia 21,25,34,35,36.

Os níveis de imunomarcação da COX-2 podem também servir como um fator preditivo, ou seja, um resultado capaz de selecionar os pacientes para determinada conduta terapêutica que nesse caso se trata de inibidores seletivos da COX-2, por exemplo, em casos onde a cirurgia não é recomendada ou onde há alto risco de metástase, atuando com função paliativa e de terapia 
ARENALES, A., BASSO, K.M. e CALDERÓN, C. Tumor de mama em cães: marcadores prognósticos e imunohistoquímica (COX-2, E-caderina, Receptores hormonais e $\mathrm{Ki}-67$ ) revisão de literatura. PUBVET, Londrina, V. 8, N. 22, Ed. 271, Art. 1806, Novembro, 2014.

adjuvante respectivamente, o que pode resultar em melhoria da qualidade de vida dos animais acometidos por neoplasias mamárias ${ }^{21,10,25,36}$.

\section{E-caderina}

As caderinas são glicoproteínas transmenbranosas que desempenham papel fundamental na embriogênese, adesão intercelular e manutenção da arquitetura tecidual. Dentre essas, se destaca a Ecaderina (E-cad), como principal responsável pela junção e manutenção das células epiteliais, e está presente em todos os tecidos ${ }^{13,23,39}$. Com finalidade de aumentar a força de adesão as E-cad possuem dois pontos de apoio (Figura 11), um intracelular, mediado por outras proteínas chamadas cateninas, e fixa ao cito esqueleto de actina (terminal $\mathrm{C}$ ), o outro é extracelular (terminal $\mathrm{N}$ ) que se adere ao ponto homólogo da mesma molécula da célula adjacente ${ }^{13,2,32,41}$.

Devido à alta incidência de neoplasias de origem epitelial em humanos e animais, a E-cad tem sido foco de diversos estudos voltados para compreensão das características biológicas das neoplasias e sua relação em situações de baixa expressão com fatores clínico patológicos e prognósticos ${ }^{23,41}$.
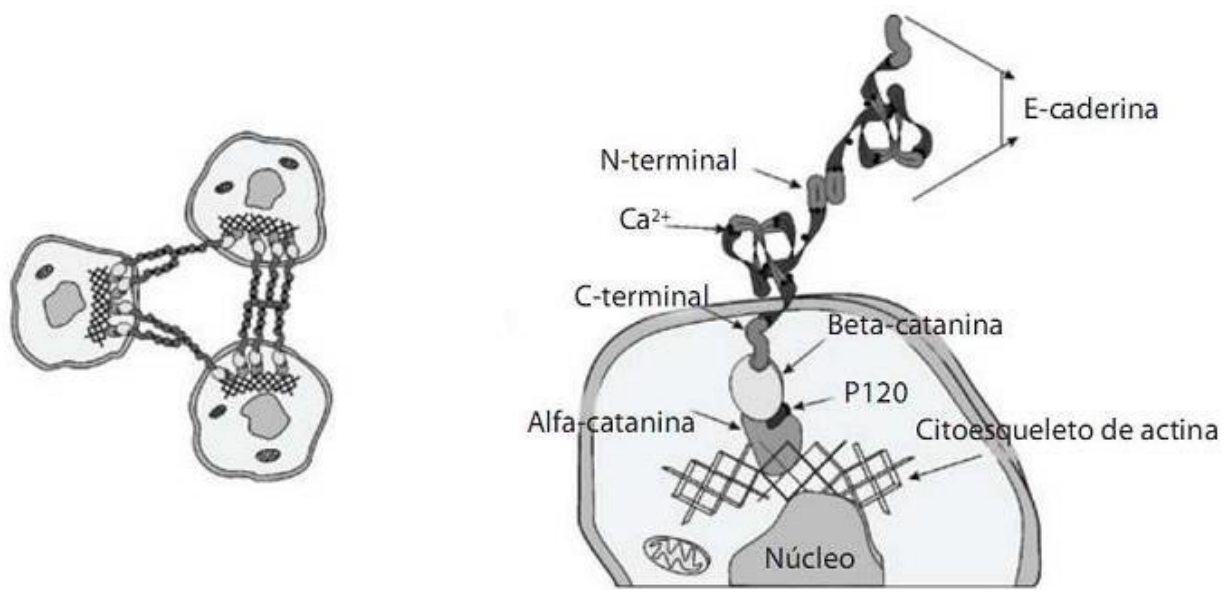

Figura 11.Representação esquemática da interação das moléculas de Ecaderina e relação com as cataninas (Fonte: PIEKARZ et al, $2008^{32}$ ). 
ARENALES, A., BASSO, K.M. e CALDERÓN, C. Tumor de mama em cães: marcadores prognósticos e imunohistoquímica (COX-2, E-caderina, Receptores hormonais e Ki-67) revisão de literatura. PUBVET, Londrina, V. 8, N. 22, Ed. 271, Art. 1806, Novembro, 2014.

A importância da avaliação da perda de expressão da E-cad na oncologia vem do envolvimento desta molécula em processos básicos da carcinogênese relacionados à ausência de organização tecidual. Assim a própria função da molécula explica a patogenia na sua ausência, pois quando expressa em menores níveis ocorre uma menor força de coesão entre as células permitindoum crescimento com menor organização, no qual há perdado controle proliferativo porcontato,facilitandoainvasãoemetástase ${ }^{3,2,13,19}$. A perda da expressão de E-cad ocorre por vários mecanismos e inclui a eliminação completa ou parcial do gene responsável, inativação por processos epigenéticos e rearranjo da cromatina ${ }^{19,41}$.

Quanto ao local da imunomarcação de E-cad em cães, as glândulas mamárias normais (Figura 12) e a maioria dos processos neoplásicos benignos (Figura 13) se apresentamsemelhantes,commarcação positivanasuperfíciebasolateraldascélulasdolúmen,ouseja, no ponto de contanto célula-célula do epitélio luminal, caracterizado como padrão membranoso 3,39,41.
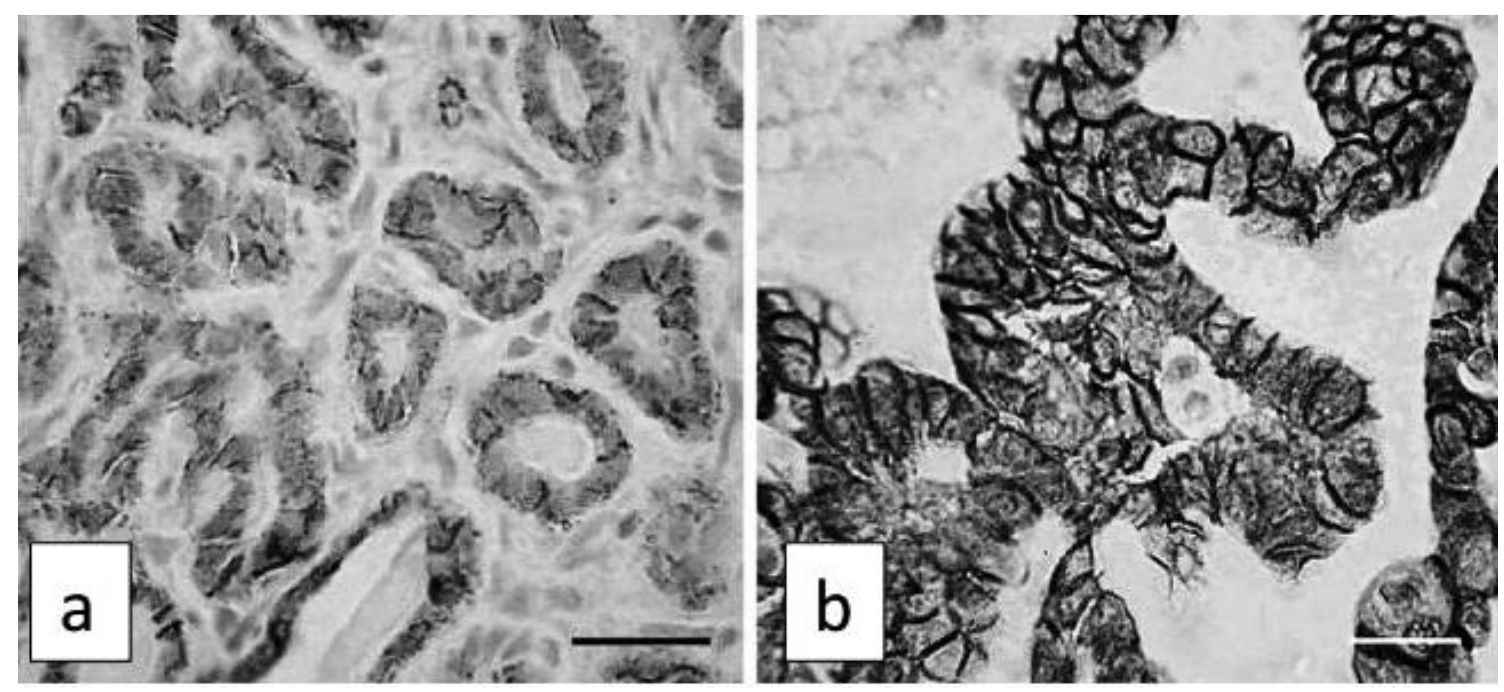

Figura 12.a. Imunoexpressão de E-caderina em glândula mamária normal com padrão basolateral das células do lúmen. Imunohistoquímica, 63x Figura 12.b Adenoma túbulo papilar. A neoplasia apresenta imunomarcação para E-caderina de maneira semelhante da glândula normal. Imunohistoquímica, 63x (Fonte: SARLI et al, 2004 ${ }^{41}$ ). 
ARENALES, A., BASSO, K.M. e CALDERÓN, C. Tumor de mama em cães: marcadores prognósticos e imunohistoquímica (COX-2, E-caderina, Receptores hormonais e Ki-67) revisão de literatura. PUBVET, Londrina, V. 8, N. 22, Ed. 271, Art. 1806, Novembro, 2014.

Nos tumores malignos ocorre uma diferença de expressão quando comparadoscom glândulas normais e neoplasias benignas, pois enquanto essas tendem a apresentar maiores níveis de marcadores na membrana, o qual é o local fisiológico, as células neoplásiasmaisindiferenciadastendemaexpressar maioresquantidadesde E-cadnocitoplasma, um local anormal,caracterizado como padrão citoplasmático (Figura 13) 13,23,38,39,41. Adicionalmente, segundo Gama et al. ${ }^{13}$, a expressão de E-caderina nas neoplasias mamárias malignas está relacionada a graduação histopatológica, e apesar da ausência de correlação estatística, existe uma tendência de menor expressão membranosa que acompanha aindiferenciação celular e consequentemente a graduação histopatológica.

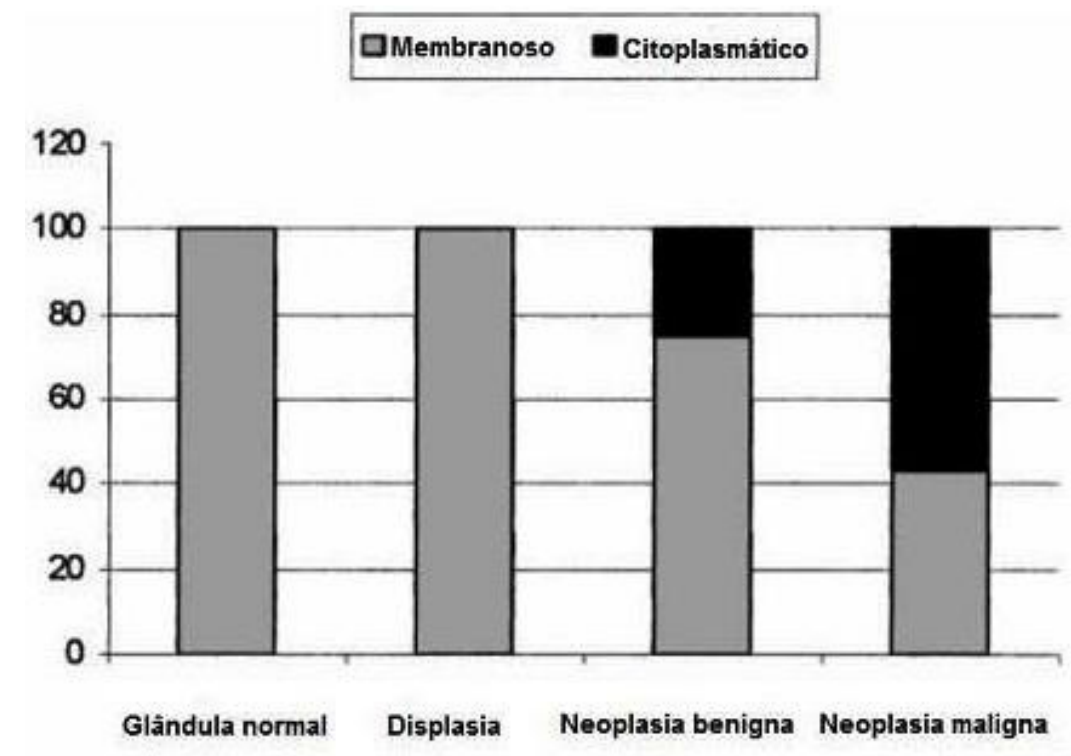

Figura 13. Relação entre os padrões de distribuição de E-Caderina de acordo com o comportamento biológico da amostra (Adaptado de Sarli et al, $2004^{41}$ ).

O porque da E-caderina ser encontrada no citoplasma de neoplasias malignas ainda não está elucidado, porém existem hipoteses de defeitos na aderência da moléculana membrana citoplasmática associada a um comprometimento na ligação com as cateninas ${ }^{41}$. 
ARENALES, A., BASSO, K.M. e CALDERÓN, C. Tumor de mama em cães: marcadores prognósticos e imunohistoquímica (COX-2, E-caderina, Receptores hormonais e Ki-67) revisão de literatura. PUBVET, Londrina, V. 8, N. 22, Ed. 271, Art. 1806, Novembro, 2014.

Matos et $\mathrm{al}^{23}$ e Gama et $\mathrm{al}^{13}$ descrevem vários achados clínico patológicos e mostram que a baixa expressão membranosa de E-caderina está relacionada a maiores áreas de necrose tumoral, tamanho, ulceração, índice mitótico, invasão de tecidos adjacentes e vasos, crescimento infiltrativo, maiores chances de metástase em linfonodos e maior indiferenciação estrutural avaliado pela graduação histopatológica.

Quando se compara a E-cad com a classificação histopatológica, ocorrem diferenças de expressão que são facilmenteexemplificadas por dois tipos de tumores malignos, primeiro os tubulopapilíferos (Figura 14) com alta expressão de E-cad, que está relacionada à maior elaboração da arquitetura tecidual, e segundo os sólidos (Figura 15), com baixa expressão, onde a arquitetura característica do tecido de origem está completamente ausente $^{13,38,39,23}$.
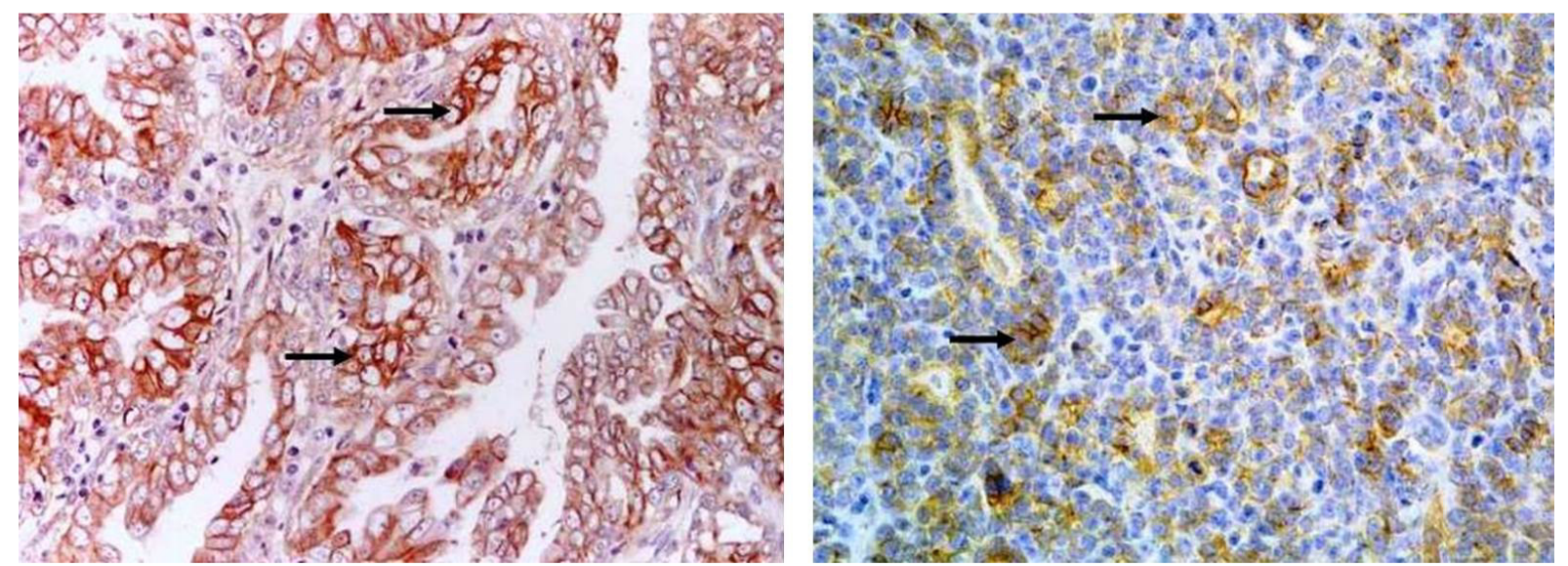

Figura 14. (Carcinoma tubulopapilífero) Alto nível de expressão de Ecaderinas (setas) em neoplasias com arranjos teciduais elaborados. Cão. Imunohistoquímica 400x.Figura 15. (Carcinoma sólido) Baixa expressão de Ecaderina (setas) relacionada à ausência de arquitetura tecidual elaborada. Cão. Imunohistoquímica 400x (Fonte: MATOS et al, 2006a ${ }^{23}$ ).

Quanto a imunoexpressão de E-cad em metástases, Brunetti et al. ${ }^{3}$ avaliaram de forma comparada as quantidades expressas entre o tumor primário e as metástases nos linfonodos regionais, eo resultado foi uma significativa diferença dos níveis de expressão entre eles, onde tumores primários 
ARENALES, A., BASSO, K.M. e CALDERÓN, C. Tumor de mama em cães: marcadores prognósticos e imunohistoquímica (COX-2, E-caderina, Receptores hormonais e Ki-67) revisão de literatura. PUBVET, Londrina, V. 8, N. 22, Ed. 271, Art. 1806, Novembro, 2014.

apresentaram menor expressão de E-cad quando comparados aos focos metastáticos.A perda da expressão de E-caderina é um pré requisito para a ocorrer a metástase, porém se presume que é umamodificação temporária, e ocorre somente na fase inicial de clonagem das células neoplásicas do tumor primário, assim, a reexpressão é um processo necessário para a adesão e estruturação das células metastáticas em órgãos distantes ${ }^{3}$.

Gama et al. ${ }^{13}$ avaliaram o tempo de sobrevida total e o período livre da doença com relação a quantidade imunoexpressão de membrana de E-cad e distribuíram os animais em dois grupos: E-cad preservada e E-cad reduzida na membrana. O resultado mostrou que a redução da E-caderina causa uma queda significativa no tempo de sobrevida (figura16) e do tempo livre da doença (figura17). Assim foi demonstrado que a perda da principal molécula de adesão celular, a E-caderina, além de relacionada a importantes fatores clínicopatológicos, está diretamente ligada a um pior prognóstico.
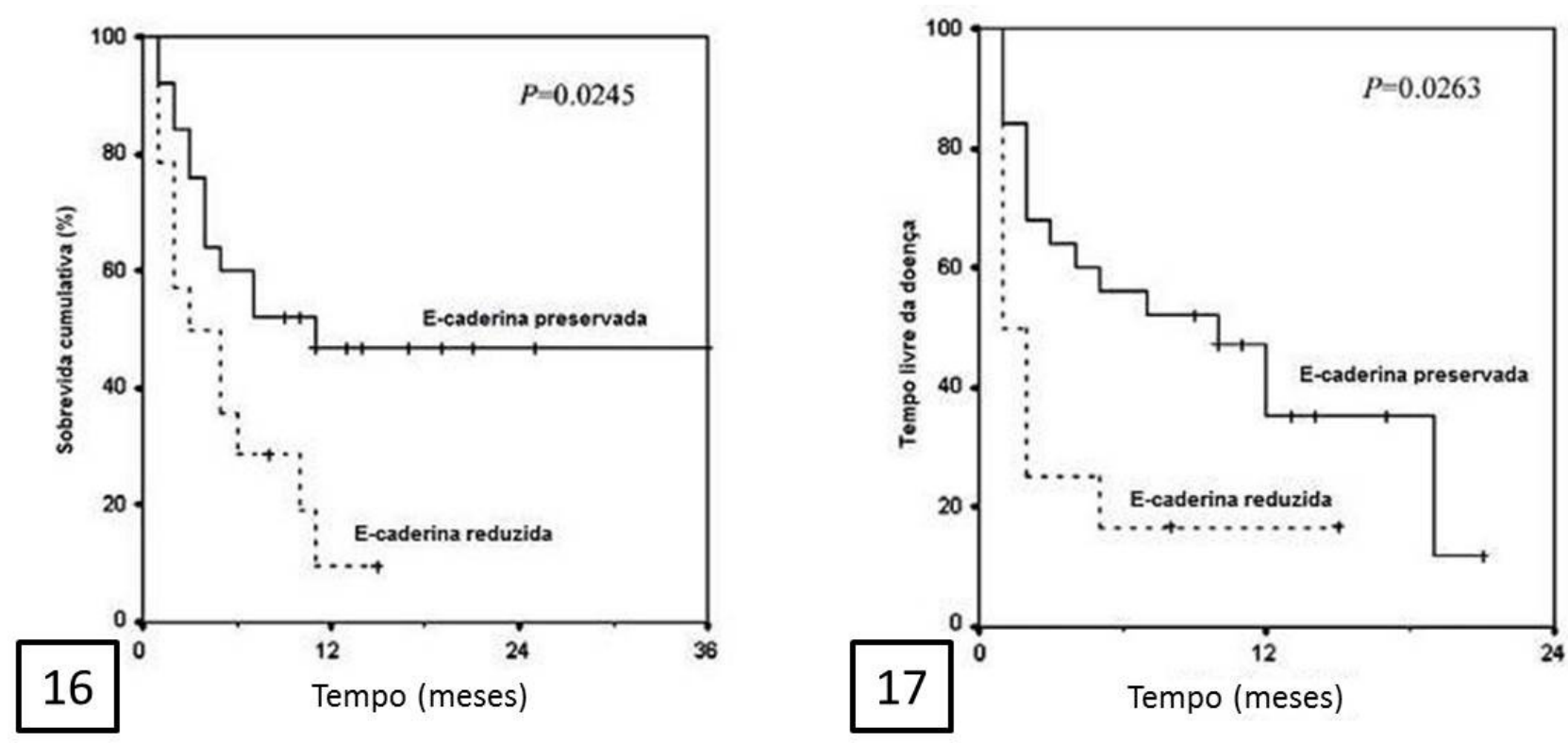

Figura 16.Sobrevida total em relação à expressão de E-caderina em neoplasias mamárias malignas. Figura 17. Tempo livre da doença em relação à expressão de E-caderina em neoplasias mamárias malignas. (Adaptado de Gama et al, 2008 ${ }^{13}$ ). 
ARENALES, A., BASSO, K.M. e CALDERÓN, C. Tumor de mama em cães: marcadores prognósticos e imunohistoquímica (COX-2, E-caderina, Receptores hormonais e Ki-67) revisão de literatura. PUBVET, Londrina, V. 8, N. 22, Ed. 271, Art. 1806, Novembro, 2014.

\section{4. $\mathrm{Ki}-67 / M I B-1$}

A velocidade de crescimento é um parâmetro importante na previsão do comportamento biológico das neoplasias mamárias e que na prática clínica é um critério difícil de ser avaliado, entretanto a imunohistoquímica é capazde mensurar o crescimento tumoral ${ }^{1}$ e dentre os vários marcadores para a análise da proliferação celular, destaca-se o Ki-67, reconhecido pelo anticorpo MIB-1, que se caracteriza por uma proteína nuclear não histona expressa no ciclo celular nas fases G1, S, G2 (Intervalo 1, síntese e intervalo 2 ) e mitose, sendo detectável uma hora após a fasede mitose $\mathrm{e}^{17,30,40,44,49}$.

A expressão do imunomarcador MIB-1, estreitamente relacionado a proliferação celular, possui importância como complemento ao diagnóstico histopatológico, permitindo uma avaliação mais criteriosa por meio da análise da razão entre as células em ciclo proliferativo e as células totais, chamada de da fração de crescimento $^{40}$. Nas neoplasias mamárias de humanos, a expressão de Ki-67 é correlacionada com diversos fatores clínicopatológicos, inclusive a interação com outros marcadores como os receptores de estrógeno e pode ainda prever se o uso da quimioterapia será benéfico parao paciente $^{40,49}$. Nos cães também existe correlação entre altos níveis de expressão de Ki-67, como por exemplo: na indiferenciação celular, classificação histopatológica (Figuras 18 e 19) e o índice mitótico emostram também que há uma relação lógica de aumento da proliferação celular com o comportamento expansivo e proliferativo das neoplasias ${ }^{1,17,22,40,49}$. Outros critérios clínico patológicos associados a maior proliferação celular evidenciado pelo Ki-67 são: ulceração, maior tamanho e infiltração em tecidos adjacentes $^{30,44,22}$. 
ARENALES, A., BASSO, K.M. e CALDERÓN, C. Tumor de mama em cães: marcadores prognósticos e imunohistoquímica (COX-2, E-caderina, Receptores hormonais e Ki-67) revisão de literatura. PUBVET, Londrina, V. 8, N. 22, Ed. 271, Art. 1806, Novembro, 2014.
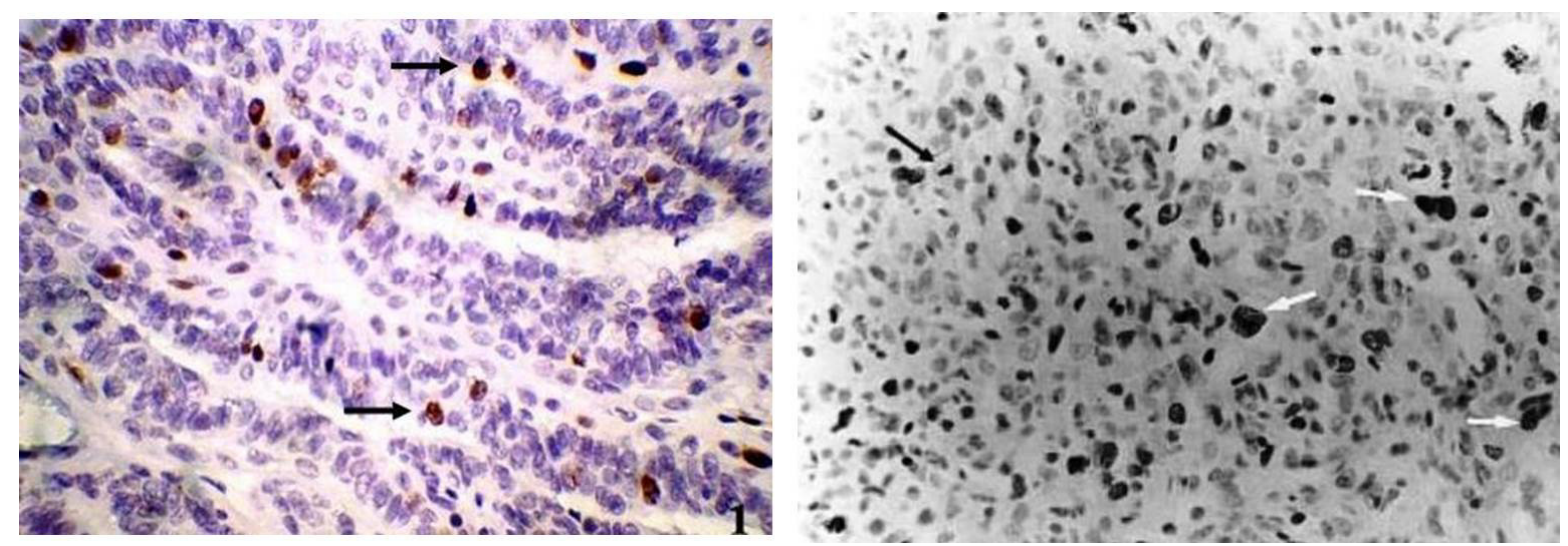

Figura 18. (Carcinoma túbulopapilar) Imunomarcação para KI-67 restrita ao núcleo (setas). Cão. Imunohistoquímica. 400x.(Fonte: KADTHUR, $2011^{17}$ )Figura 19. (Carcinoma sólido) Alta imunoexpressão de Ki-67, mitoses (seta preta) e núcleos positivos (setas brancas). Cão. Imunohistoquímica (Fonte: PEÑA et $a l, 1998^{30}$ ).

A expressão de Ki-67 nas neoplasias de cães ocorre de forma restrita ao núcleo, nos padrões difuso, granular, nucleolar ou misto, além da evidenciação do nucléolo e maior número de células positivas na região periférica do tumor $^{17,22,30,40}$. A expressão de Ki-67 é proporcional ao grau de malignidade da neoplasia, porque a proliferação celular aumenta junto com a sua indiferenciação, ou seja, quanto mais maligno o tumor, mais as células se proliferam, exemplificado pelo aumento gradativo de expressão em adenocarcinomas até carcinomas sólidos ${ }^{30}$.

Segundo Amorim et al. ${ }^{1}$ os carcinomas inflamatórios, com comportamento extremamente agressivo, tem altas taxas de proliferação celular mensurada por imunomarcação para Ki-67.Quanto a metástases, Peña et al. ${ }^{30}$ relatam uma expressão significativa de positividade para MIB-1 com o relação ao acometimento de linfonodos, e os autores concluem que o expressão de Ki-67 é um marcador para previsão de metástases, por quequando ocorre expressão positiva em mais que $24 \%$ das células, a probabilidade de metástase aumenta para $99 \%$.

Kadthur et al. ${ }^{17}$ concluiu um valor de corte $(14,27$ por campo) para a expressão de Ki-67 nas neoplasias mamárias de cadela, podendo assim separar os 
ARENALES, A., BASSO, K.M. e CALDERÓN, C. Tumor de mama em cães: marcadores prognósticos e imunohistoquímica (COX-2, E-caderina, Receptores hormonais e Ki-67) revisão de literatura. PUBVET, Londrina, V. 8, N. 22, Ed. 271, Art. 1806, Novembro, 2014.

tumores em dois grupos, os de alta expressão e de baixa expressão, este resultado foi possível porque esse marcador pode ser correlacionado diretamente ao prognóstico (Figura 20) e o grupo de animais com tumores de baixa contagem positiva apresentou melhor sobrevida quando comparados aos de alta contagem positiva. Tais dados mostram, portanto significativa aplicabilidade da análise da proliferação celular pelo Ki-67.

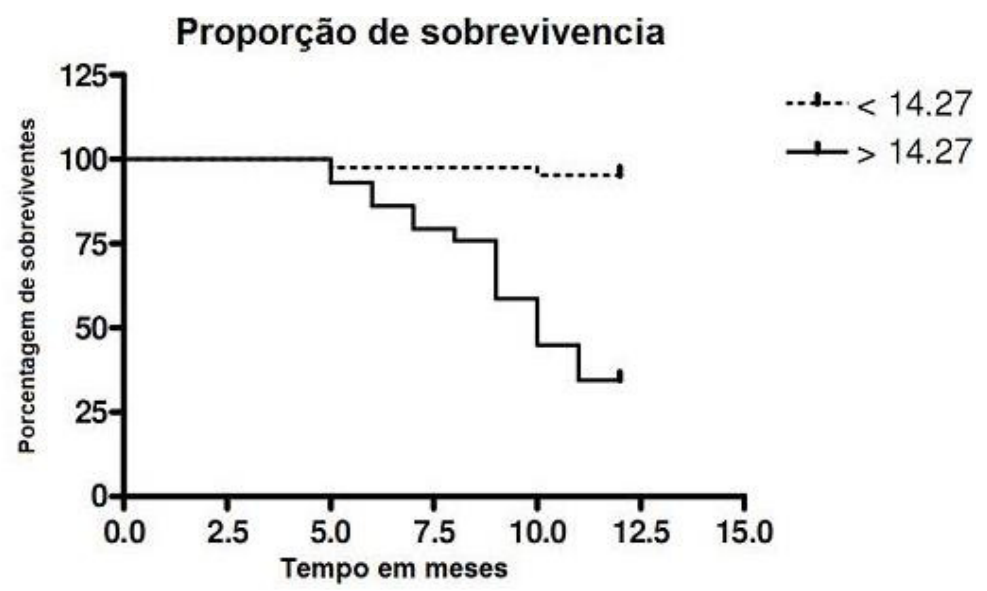

Figura 20. Demonstração do tempo de sobrevida em relação à imunoexpressão de acordo com o valor de corte estabelecido por Kadthur (2011) (KADTHUR et al, 2011 ${ }^{17}$ ).

\section{Receptores hormonais}

Os hormônios ovarianos participam de maneira fundamental na fisiologia da glândula mamária e do mesmo modo estão relacionados ao desenvolvimento das neoplasias mamárias ${ }^{6,18,42}$. Os principais hormônios com participação na multiplicação celular são os estrógenos e as progesteronas, sendo seus principais receptores imunohistoquímicos caracterizados respectivamente por: ERa (Receptor de estrógeno alfa) e PR (Receptor de progesterona) $)^{6,18,42}$.

Nos seres humanos a função dos receptores hormonais Era e PR estão descritas com valorprognóstico em relação ao tempo de sobrevida, tempo livre 
ARENALES, A., BASSO, K.M. e CALDERÓN, C. Tumor de mama em cães: marcadores prognósticos e imunohistoquímica (COX-2, E-caderina, Receptores hormonais e Ki-67) revisão de literatura. PUBVET, Londrina, V. 8, N. 22, Ed. 271, Art. 1806, Novembro, 2014.

da doença e a proliferação celular além de valor preditivo associado ao uso de terapia com moduladores hormonais ${ }^{28,42}$.

Em cadelas, a imunomarcação para ambos os receptores, ERa e PR, ocorrem de maneira restrita ao núcleo $0^{6,7,28}$ esegundo Chang et al. (6) a imunomarcação destes receptores em células normais ocorre de maneira homogênea e apenas as células neoplásicas mostram intensidade variável, porém Nieto et al. $^{28}$ descrevem evidente heterogeneidade de expressão nas glândulas normais e neoplásicas, e atribui este fato as diferenças de atividade metabólica entre as células.

Os níveis de expressão de ERa e PR estão associados ao comportamento biológico analisado pela morfologia histopatológica, onde ocorrem maiores níveis de imunomarcação em tumores benignos em comparação aos malignos (Figuras 21, 22, 23 e 24) 6,14,7,25,28.

Quando avaliados conjuntamente, as expressões de ambos os receptores, Erae PR, mostraram que a maioria dos tumores benignospossui imunomarcação positiva para os dois receptores, ou seja, mais próximo da célula normal, enquanto os tumores malignos expressam, em sua maioria, Eranegativo e PR positivo ${ }^{6,7}$.

A quantidade de receptores hormonais são relacionados à classificação histopatológica quanto à presençado componente mesenquimal, assim as neoplasias caracterizadas como complexas ou mistas possuem maiores níveis de expressão desses marcadores quando comparada aostumores classificados como simples, ou seja, sem o componente mesenquimal. Do mesmo modo ocorrem menores níveis de expressão em tumores indiferenciados, representado pelos carcinomas sólidos e sarcomas, quando comparados com adenocarcinomas ${ }^{6,7,28}$. 
ARENALES, A., BASSO, K.M. e CALDERÓN, C. Tumor de mama em cães: marcadores prognósticos e imunohistoquímica (COX-2, E-caderina, Receptores hormonais e Ki-67) revisão de literatura. PUBVET, Londrina, V. 8, N. 22, Ed. 271, Art. 1806, Novembro, 2014.
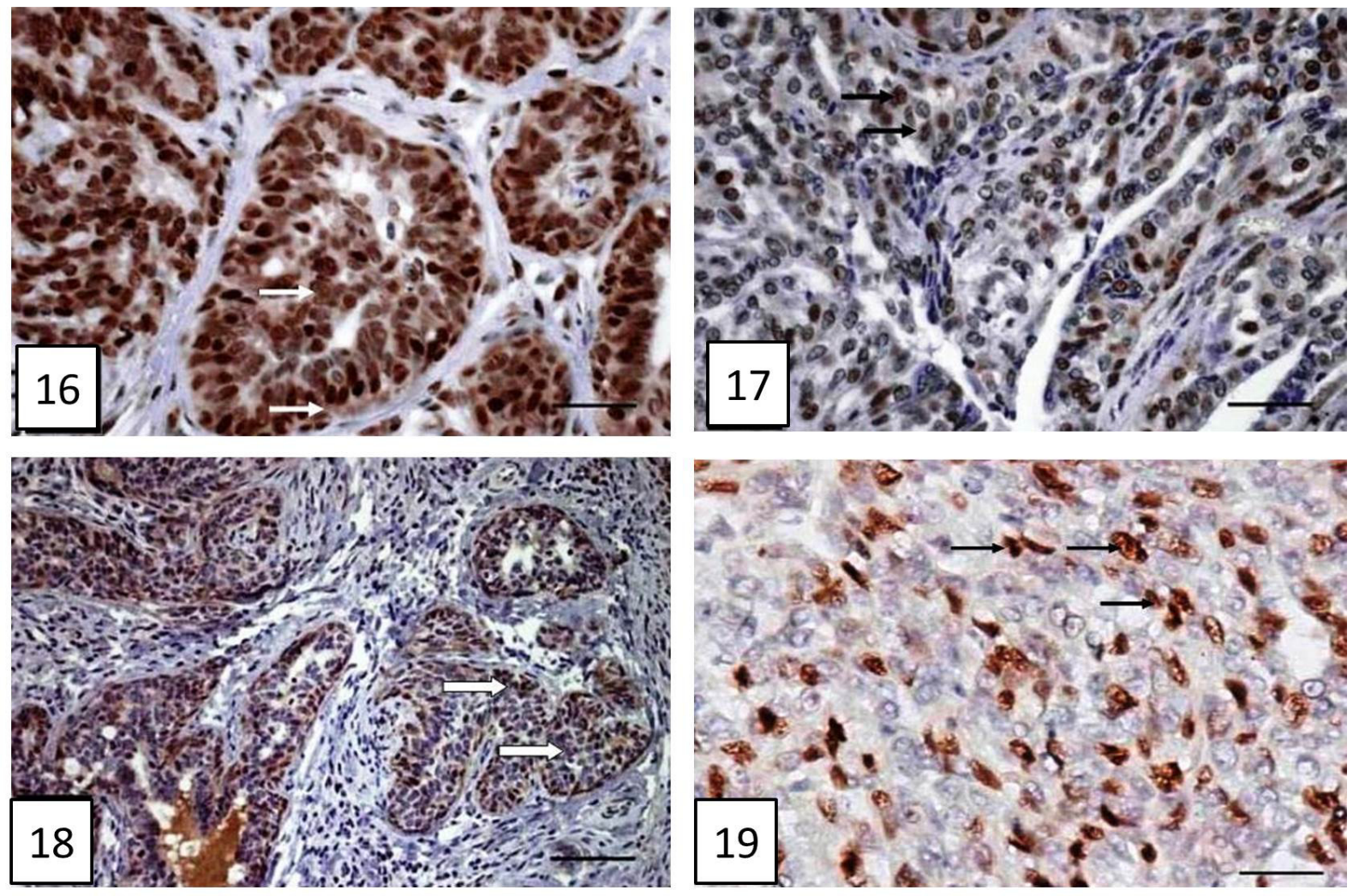

Figura 21. (Adenoma) Expressão de ERa em neoplasia benigna. Intensa imunomarcação restrita ao núcleo das células epiteliais (setas). Cão. Imunohistoquímica. Barra equivale a $150 \mu \mathrm{m}$ (Fonte: MILLANTA et al, $2005^{24}$ ).Figura 22. (Carcinoma simples tubulopapilar) Expressão de ERa (setas) em neoplasia maligna. Evidente heterogeneidade e baixo nível de expressão. Cão.Imunohistoquímica. Barra equivale a $150 \mu \mathrm{m}$ (Fonte: MILLANTA, et al, $2005^{24}$ ).Figura 23. (Neoplasia benigna) Núcleos corados de forma heterogenia (setas) parao imunomarcador PR. Cão. Imunohistoquímica. Barra equivale a $240 \mu \mathrm{m}$ (Fonte: MILLANTA et al, $2005^{24}$ ).Figura 24. (Carcinoma sólido) Imunomarcação intensa para PR (setas) em neoplasias de comportamento biológico malignas. Imunohistoquímica. Barra equivale a $25 \mu \mathrm{m}$ (Fonte: CHANG et al, 20096).

A indiferenciação celular comparada aos níveis de receptores hormonais foi demonstrada em dois trabalhos: Amorimet al. ${ }^{1}$ que avaliaram a expressão de receptores hormonais em carcinomas inflamatórios, e obteve total ausência destes, e De Las Mulas et al. ${ }^{7}$ o qual associou a graduação histopatológica com a expressão de Erae $P R$, e os resultados mostraram que os graus 
ARENALES, A., BASSO, K.M. e CALDERÓN, C. Tumor de mama em cães: marcadores prognósticos e imunohistoquímica (COX-2, E-caderina, Receptores hormonais e Ki-67) revisão de literatura. PUBVET, Londrina, V. 8, N. 22, Ed. 271, Art. 1806, Novembro, 2014.

histopatológicos mais baixos (I e II) tendem a expressar menores quantidadesdos receptores.

Segundo DeLasMulas et al. ${ }^{7}$ quando um ou ambos receptores estão presentes em neoplasias malignas os tumores são frequentemente menores que três centímetros, possuem ausência de infiltração vascular, menores áreas de necrose e maior infiltrado linfocítico.De acordo com Nieto et al. ${ }^{28}$ a ausência total de expressão de Era está diretamente relacionada à ocorrência de metástases em linfonodos regionais, este fato também foi demonstrado por Chang et al. ${ }^{6}$, com a análise dos graus de estadiamento clínico relacionado à imunomarcação de ambos os receptores, onde os autores encontraram maior tendência dos baixos estádios (I, II e III) apresentarem altos níveis de expressão de receptores.

A fração decrescimento celular mensurada com uso de imunohistoquímica para $\mathrm{Ki}-67$ relacionada ao Era foi estudada por Nieto et al. ${ }^{28}$ os quais mostraram que o status hormonal está inversamente relacionado ao índice proliferativo, e do mesmo modo, ao analisar somente o PR, Geraldes et al. ${ }^{14}$ observaram resultados semelhantes, com queda dos níveis de imunoexpressão e aumento da proliferação celular.

Assim ambos os autores, Geraldes et al. ${ }^{14}$ e Nieto et al. ${ }^{28}$ concluem que altas taxas de proliferação em neoplasias mamárias malignas estão acompanhadas de uma diminuição da dependência hormonal, e resulta em um crescimento celular com maior autonomia, ou seja, as células neoplásicas perdem os receptores hormonais que fisiologicamente regulariam a multiplicação celular e passam a multiplicar-se independentemente, com menos mecanismos de regulação.

Quanto ao tempo de sobrevida total e o período livre da doença,os resultados ainda são contraditórios entre os autores, Nieto et al. ${ }^{28}$ avaliou apenas o Erae demonstrou correlação inversa de ambos (OS e DFS) e o status hormonal, enquanto De Las Mulas et al. ${ }^{7}$ não encontrou relação entre o DFS e 
ARENALES, A., BASSO, K.M. e CALDERÓN, C. Tumor de mama em cães: marcadores prognósticos e imunohistoquímica (COX-2, E-caderina, Receptores hormonais e $\mathrm{Ki}-67$ ) revisão de literatura. PUBVET, Londrina, V. 8, N. 22, Ed. 271, Art. 1806, Novembro, 2014.

o ERa. Entretanto Chang et al. ${ }^{6}$ ño encontrou dados estatísticos suficientes para relacionar o DFS após um ano com o ERa, mas somente para o PR, onde relatam um maior tempo de sobrevida em tumores com altas expressões de receptores de progesterona (Figura 25).

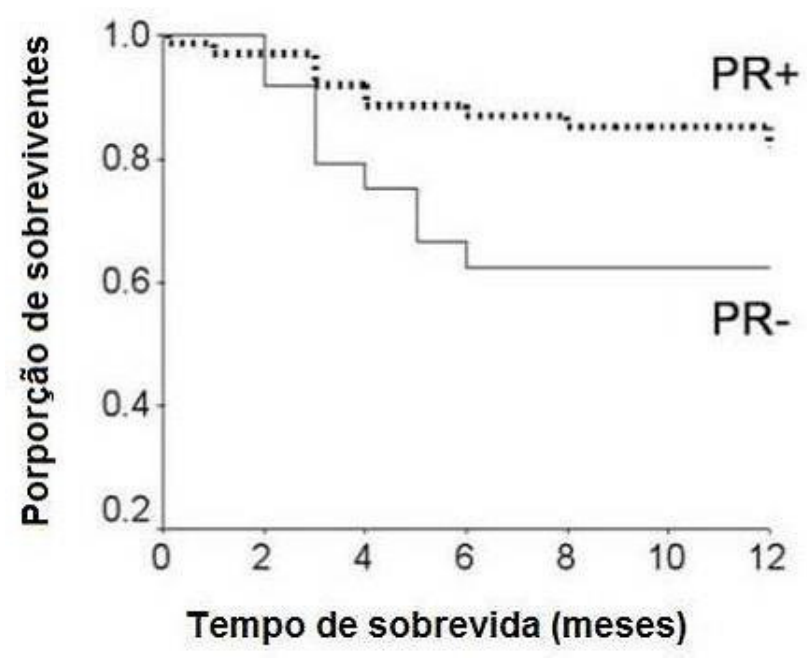

Figura 25. Aumento significativo da sobrevida relacionada a imunoexpressão de receptores de progesterona (PR) (Adaptado de Chang et al, $\left.2009^{6}\right)$.

Várias estratégias são utilizadas em humanos para bloqueio dos receptores hormonais,incluindo os SERMS (Specific Estrogen Receptor Modulators), tornando assim a expressão IHC dosErae PR um exame com valor preditivo, ou seja, se o paciente apresentar níveis altos de receptores hormonais, o uso do medicamento para bloquea-los e diminuir a multiplicação celular é recompensador. A principal droga utilizada é o tamoxifen, e nos cães seu uso ainda não é recomendado devido a efeitos colaterais, entretanto a alta expressão de PR possibilita o uso de antagonistas deste receptor e o uso de cadelas como modelo para experimentação de terapias hormonais adjuvantes ${ }^{7,20,42}$. 
ARENALES, A., BASSO, K.M. e CALDERÓN, C. Tumor de mama em cães: marcadores prognósticos e imunohistoquímica (COX-2, E-caderina, Receptores hormonais e Ki-67) revisão de literatura. PUBVET, Londrina, V. 8, N. 22, Ed. 271, Art. 1806, Novembro, 2014.

\section{Conclusões}

Vista a grande variabilidade do comportamento biológico das neoplasias mamárias e a significativa chance de falhas de previsão dos fatores prognósticos ditos "clássicos", a imunohistoquímica, a qual inclui diversos marcadores, caracteriza-se hoje como uma excelente ferramenta para auxiliar na determinação do prognóstico, abrangendo a sobrevida total e o período livre da doença, além de modificar o tratamento, elucidando fatores preditivos.

Assim, apesar da relativa escassez de trabalhos com análise da sobrevida relacionada aos imunomarcadores nas cadelas, é possível visualizar um grande campo de atuação para os anatomopatologistas veterinários, em decorrência daalta frequência das neoplasias mamárias associada a alta mortalidade desta e o crescente número de proprietários colaborativos.

Entretanto a aplicação correta da técnica somente ocorre quando clínicos e anatomopatologistas trabalharem em conjunto, assim apesar da eficiência da IHC ainda é necessário uma ampla comunicação dos dados entre ambas as áreas, de forma precisa e padronizada, uma vez que existe uma finalidade em comum, a qual está relacionada ao prognóstico, e este quando feito corretamente significa um tratamento mais preciso e melhor qualidade de vida para o paciente, além de proporcionar material de qualidade para estudos em oncologia veterinária e comparativa.

\section{Referências}

1. AMORIM, R.L.; SOUZA, C.H.M.; BANDARRA, E.P.; SANCHES, O.C.; PIZA, E.T. Immunohistochemical study of Estrogen and Progesterone Receptors and Cell Proliferative Indexes in Canine Inflammatory Mammary Carcinoma: 9 cases. Brazilian Journal of Veterinary Pathology.v.1, p. 16-20, 2008.

2. BRUNETTI, B.; SARLI, G.; PREZIOSI, S.; MONARI, I.; BENAZZI, C. E-cadherin and $\beta$ catenin reduction influence invasion but not proliferation and survival in canine malignant mammary tumors. Veterinary Pathology. v.42, p.781-787, 2005. 
3. BRUNETTI, B.; SARLI, G.; PREZIOSI, R.; LEPROTTI, S.; BENAZZI, C. Ecadherin expression in canine mammary carcinomas with regional lymph node metástases. Journal of Veterinary Medicine. v. 50, p. 496-500, 2003.

4. CASALLI, G.D.; LAVALLE, G.E.; DE NARDI, A.B.; FERREIRA, E.; BERTAGNOLLI, A.C.; ESTRELA-LIMA, A.; ALESSI, A.C.; DALECK, C.R.; SALGADO, B.S.; FERNANDES, C.G.; SOBRAL, R.A.; AMORIM, R.L.; GAMBA, C.O.; DAMASCENO, K.A.; AULER, P.A.; MAGALHÃES, G.M.; SILVA, J.O.; RAPOSO, J.B.; FERREIRA, A.M.R.; OLIVEIRA, L.O.; MALM, C.; ZUCCARI, D.A.P.C.; TANAKA, N.M.; RIBEIRO, L.R.; CAMPOS, L.C.; SOUZA, C.M.; LEITE, J.S.; SOARES, L.M.C.; CAVALCANTI, M.F.; FONTELES, Z.G.C.; SCHUNCH, I.D.; PANIAGO, J; OLIVEIRA, T.S.; TERRA, E.M.;CASTANHEIRA, T.L.L.; FELIX, A.O.C.; CARVALHO, G.D.; GUIM, T.N.; GUIM, T.N.; GARRIDO, E.; FERNANDES, S.C.; MAIA, F.C.L.; DAGLI, M.L.Z.; ROCHA, N.S.; FUKUMASU, H.; GRANDI, F.; MACHADO, J.P.; SILVA, S.M.M.S.; BERREZIL, J.E.; FREHSE, M.S.; ALMEIDA, E.C.P.A.; CAMPOS, C.B. Consensus for the Diagnosis, Prognosis and Treatment of Canine Mammary Tumors. Brazilian Journal of Veterinary Pathology. v.4, n.2, p.153-180, 2011.

5. CAVALCANTI, M.F.; CASSALI, G.D. Fatores prognósticos no diagnóstico clínico e histopatológico dos tumores de mama em cadelas - revisão. Clínicaveterinária. Ano XI, n.61, março/abril, 2006.

6. CHANG, C.; TSAI,M.; LIAO, J.; CHAN, J.P.; WONG, M.;CHANG, S. Evaluation of hormone receptor expression for use in predicting survival of female dogs with malignant mammary gland tumours. Journal of the American Veterinary Medical Association. v.235, n. 4, p. 391-396, 2009

7. DE LAS MULAS, J. M.; MILLÁN, Y.; DIOS, R. A prospective analysis of immnohistochemically determined estrogen receptor $a$ and progesterone receptor expression and host and tumor factors as predictors of disease-free period in mammary tumors of the dog. Veterinary Pathology. v.42, p. 200-212, 2005.

8. DIAS PEREIRA, P.; LOPES, C.C.; MATOS, A.J.F.; SANTOS, M.; GARTNER, F.; MEDEIROS, R.; LOPES, C. COX-2 expression in canine normal and neoplastic mammary gland. Journal of comparative pathology. v.140, p.247-253, 2009.

9. DORÉ, M. Cycooxygenase-2 expression in animal cancers. Veterinary pathology. V.48, p.254-265, 2011.

10.DORÉ, M.; LANTHIER, I.; SIROIS, J. Cyclooxygenase-2 expression in canine mammary tumors. Veterinary pathology. v.40, p.207-212, 2003.

11. FONSECA C. S.; DALECK, C.R. Neoplasias mamárias em cadelas: influência hormonal e efeitos da ovário-histerectomia como terapia adjuvante. Ciência Rural, Santa Maria. v.30, n.4, p.731-735, 2000.

12. FOSSUM, T. Cirurgia dos sistemas Reprodutivo e Genital. In: Cirurgia de pequenos animais. 3ed. Rio de Janeiro: Mosby, 2007, p. 729-735.

13. GAMA, A.; PAREDES, J.; GARTNER, F.; ALVES, A.; SCHMITT, F. Expression of ecadherin, $\mathrm{p}$-cadherin, and $\beta$-catenin in canine malignant mammary tumoursin relation to clinicopathological parameters, proliferation and survival. The Veterinary Journal. v.177, p. 45-52, 2008. 
14. GERALDES M.; GÄRTNER, F.; SCHMITT, F. Immunohistochemical study of hormonal receptors and cell proliferation in normalcanine mammary glands and spontaneous mammary tumours. Veterinary Records. v.146, p 403-406, 2000.

15. GOLDSCHIMIDT, M.; PEÑA, L.; RASOTTO, R.; ZAPPULLI, V. Classification and grading of canine mamary tumors. Veterinary pathology. v.48, p.117-131, 2011.

16. HELLER, D.A.; CLIFFORD, C.A.; GOLDSCHMIDT, M.H.; HOLT, D.E.; SHOFER, F.S.; SMITH, A.; SORENMO. Cyclooxygenase-2 expression is associated with histologic tumor type in canine mammary carcinoma. Veterinary Pathology. v.42, p.776$780,2005$.

17. KADTHUR, J. C.; RAO, S.; SONNAHALLIPURA, B. M.; THIMMANAHALLI, D.S.; LAXMIKANTH, M. Prognostic value of Ki-67 proliferation antigen in canine malignant mammary gland tumours. Brazilian Journal of Veterinary Pathology. v.4, p.36-40, 2011.

18. KAMARAGURUPARAN, R.; PRATHIBA, D.; NAGINI, S. Of humans and canines: immunohistochemical analysis of PCNA, Bcl-2, p53, cytokeratin and ER in mammary tumours. Research in Veterinary Science. v.81, p. 218-224, 2006.

19. KNUDSEN, K.A.; WHEELOCK, M.; Cadherins and the mammary gland. Journal of cellular biochemistry. v.95, p.488-496, 2005.

20. LANA, S.E.; RUTTERMAN G.R.; WITHROW, S.J. Tumors ofthe Mammary Gland In: WITHROW, SJ.; VAIL, D.M. Small Animal Clinical Oncology. 4ed. St Louis: Saunders, 2007. p. 619-633.

21. LAVALLE, G.E.; BERTAGNOLLI， A.C.; TAVARES, W.L.F.; CASSLI， G.D. Cox-2 expression in canine mammary carcinomas: correlation with angiogenesis and overall survival. Veterinary Pathology. v.46, p.1280-1280, 2009.

22. MATOS, A.J.F.; LOPES, C.C.C.; FAUSTINO, A.M.R.; CARVALHEIRA， J.G.V.; DOS SANTOS, M.S.A.; RUTTEMAN, G.R.; GARTNER, M.F.R.M. MIB-1 labelling índices according to clinico-pathological variablesin canine mammary tumours: a multivariate study. Anticancer research. v.26, p. 1821-1826, 2006b.

23. MATOS, A.J.F.; LOPES, C.; CAVALHEIRA, M.S.; RUTTEMAN, G.R.; GARTNER, F. Ecadherin expression in canine malignant mammary tumours: relationship to other clinico-pathological variables. Journal of comparative pathology. v.134, p.182189, 2006a.

24. MILLANTA, F.; CALANDRELLA, M.; BARI, G.; NICCOLINI, M.; VANNOZZI, I.; POLI, A. Comparison of steroid receptor expression in normal, dysplasic, and neoplasic canine and feline mammary tissues. Research in Veterinary Science. v.79, p. 225$232,2005$.

25. MILLANTA， F.; CITI， S.; DELLA SANTA, D.; PORCIANI, M.; POLI, A. COX-2 expression in canine and feline invasive mammary carcinomas: correlation with clinicopathologicalfeathures and prognostic molecular markes. Breast cancer research and tratament. V.98, p.115-120, 2006.

26. MISDORP, W. Tumors of the Mammary Gland. In: D.J, Meuten. Tumors in Domestic Animals, 4ed. Iowa: Blackwell, 2002 p. 575-607. 
27.MORRIS, J.S.; DOBSON, J.M.; BOSTOCK, D.E.; O'FARRELL, E.O. Effect ofOvariohysterectomy in Bitches With Mammary Neoplasms. The Veterinary Records, v.142, p.656-658, 1998.

28. NIETO, A.; PEÑA, M.D.; PEREZ ALENZA, M.A.; FLORES, J.M.; CASTAÑO. Immunohistologic detection of estrogen receptor alpha in canine mammary tumours: clinical pathologic associations and prognostic significance. Veterinary Pathology. v.37, p. 239-247, 2000.

29. PELETEIRO, M.C. Tumores Mamários na Cadela e na Gata. Revista Portuguesa de Ciências Veterinárias, v. 89, n.809, p.11-29, 1994.

30. PEÑA, L.L.; NIETO, A.I.; PEREZ ALENZA, D.; CUESTA, P.; CASTAÑo, M. Immunohistochemical detection of $\mathrm{Ki}-67$ and PCNA in canine mammary tumors: relationship to clinical and pathologic variavles. Journal of veterinary diagnostic investigation. v.10, p.237-246, 1998.

31. PEREZ ALENZA, M.D.; PEÑA, L.; DEL CASTILLO, N.; NIETO, A.I. Factors Influencing the Incidence and Prognosis of Canine Mammary Tumours. Journal of Small Animal Pratice, v.41, p.287-291, 2000.

32.PIERKARZ, C.H.; BIONDO, A.W.; AMORIM, R.L.; RODASKI, S.; BARROS FILHO, I.R.; DE NARDI, A.B. Expressão das caderinasnos tumores mamários em cadelas. Archives of Veterinary Science. v.13, n.1, p.12-21, 2008.

33. QUEIROGA, F.; LOPES, C. Tumores Mamários caninos - Novas Perspectivas. In: Congresso deCiênciasVeterinárias, 2002. Oeiras. Proceedings of the Veterinary Sciences Congress, 2002. p. 183-190.

34. QUEIROGA， F.L.; PEREZ ALENZA, M.D.; SILVAN, G.; PEÑA, L.; LOPES, C.; ILLERA, J. C.; Cox-2 levels in canine mammary tumors, including inflammatory mammary carcinoma: clinicopathological features and prognostic significance. Anticancer research. v.25, p. 4269-4276, 2005.

35. QUEIROGA, F.L.; ALVES, A.; PIRES, I.; LOPES, C. Expression of Cox-1 and Cox2 in canine mammary tumours.Journal of comparative pathology.v.136, p. 136-185, 2007.

36. QUEIROGA, F.L.; PIRES, I.; LOBO, L.; LOPES, C.S. The role of Cox-2 expression in the prognosis of dogs with malignant mammary tumours. Research in veterinary science. $v .88$, p.441-445, 2010.

37. RAMOS-VARA, J.A. Technical aspects of immunohistochemistry. Veterinary pathology.v.42, p.405-426, 2005.

38. REIS, A.L.; CARVALHEIRA, J.; SCHMITT, F.C.; GARTNER, F. Immunohistochemical study of the expression of e-cadherin in canine mammary tumours. Veterinary Records. v.152, p.621-624, 2003.

39. RESTUCCI, B.; PAPPARELLA, S.; VICO, G.; MAIOLINO, P. E cadherin expression in normal and neoplastic canine mammary gland. Journal of comparative pathology. v.116, p. 191-202, 1997. 
40.SARLI， G.; PREZIOSI， R.; BENAZZI， C.; CASTELLANI， G.; MARCATO, P.S. Prognostic value of histologic stage and prliferative activity in canine malignant mammary tumors. Journal of veterinary diagnostic investigation. v.14, p. 14-25, 2002.

41.SARLI， G.; PREZIOSI, R.; TOLLA, L.; BRUNETTI, B.; BENAZZI, C. E-cadherin immunoreactivity in canine mammary tumors. Journal of veterinary diagnostic investigation. v.16, p.542-547, 2004.

42. SORENMO, K; Canine Mammary Glands. The Veterinary Clinics Small Animal Pratice, v. 33, p. 573-596, 2003.

43. SORENMO, K.U.; RASOTTO, R.; ZAPPULLI, V.; GOLDSCHMIDT, M.H. Development, anatomy histology, lymphatic drainage, clinical features, and cell differentiation markers of canine mammary gland neoplasms. Veterinary pathology. v.48, p. 85-97, 2010.

44.TERZIAN, A.C.B.; ZUCARRI, D.A.P.C.; PEREIRA, R.S.; PAVAM, M. V.;RUIZ, C.M.;SUEIRO, F.A.R.; COELHO, J. Avaliação da caspase-3 e Ki-67 como marcadores prognósticos nas neoplasias mamárias em cadelas. Brazilian Journal Veterinary Research and Animal Science. v.44, n.2, p.96-102, 2007.

45. WITHROW, S.J. Why Worry About Cancer in Pets? In:

Small Animal Clinical Oncology. 4ed. St Louis: Saunders, 2007. p. 15-16.

46. YAMAGAMI, T.; KOBAYASHI, T.; TAKAHASHI, K.; SUGIYAMA, M. Prognosis for Canine Malingnant Mammary Tumors Based on TNM and Histologic Classification. Journal of Veterinary Medicine Science, v.58, p.1079-1083, 1996.

47.ZUCCARI, D.A.P.C; BERTON, C.R.; TERZIAN, A.C.B.; RUIZ, C.M. Fatores prognósticos e preditivos nas neoplasias mamárias - importância dos marcadores imuno-histoquímicos nas espécieshumana e canina - estudo comparativo. Arquivo de ciência e saúde. v.15, p. 189-198, 2008a.

48. ZUCCARI, D.A.P.C.; PAVAM, M. V.; TERZIAN, A. C.; PEREIRA, R.S.; RUIZ, C.M.; ANDRADE, J.C. Immunohistochemical evaluation of e-cadherin, Ki-67, and PCNA in canine mammary neoplasias: correlation of prognostic factors and clinical outcome. PesquisaVeterináriaBrasileira. v.28, p.207-215, 2008b.

49. ZUCCARI, D.A.P.C.; SANTANA, A.E.; CURY, P.M.; CORDEIRO, J.A. Immunocytochemical study of $\mathrm{Ki}-67$ as a prognostic marker in canine mammary neoplasia.Veterinary Clinical Pathology. v.33, n.1, p. 23-28, 2004.

50. ZUCCARI, D.A.P.C.; SANTANA, A.E.; ROCHA, N.S.; Correlação Entre a Citologia Aspirativa por Agulha Fina e a Histologia no Diagnóstico de Tumores mamários de Cadelas. Brazilian Journal of Veterinary Research and Animal Science, v.38, n.1, p. 38-41, 2001. 